\title{
EXPERIENCE WITH VACCINE IN THE PREVENTION OF WHOOPING COUGH *
}

FRANK VANDER BOGERT, M.D.

SCHENECTADY, N. Y.

Since the value of vaccine in the prevention and treatment of whooping cough is still not generally admitted, although the burden of proof seems unquestionably in its favor, the following experience with its use as a prophylactic measure seems worthy of report.

At the Children's Home in Schenectady, one of the forty-six inmates developed whooping cough on or about Nov. 27, 1917, but because of failure of diagnosis was allowed to mingle for nearly a week with other children, after which he was isolated in a separate building. It was later learned that during this time he was known to have whooped and vomited.

With the view of undertaking measures to prevent spread of the infection through the Home, an effort was made to confirm absolutely the diagnosis. An epidemic of the disease was well under way in the city at the time, and several of the whooping cough patients had been attending the school to which the children of the Home were sent daily, and at the time of writing, seven weeks after the development of the case, there were nearly 400 records of pertussis at the City Health Department, and the number of unreported cases, of course, cannot be ascertained.

As confirmatory evidence of the correctness of the diagnosis, the child was said to have whooped and was known to have vomited with the cough. A blood count showed a lymphocytosis of 61 per cent., and a smear from the pharynx gave many gram-negative bacilli, reported as suspicious of the Bordet-Gengou type.

Having apparently confirmed the diagnosis, the histories of the other inmates were examined for past record of the disease. Of these, thirty-one gave no record of having had whooping cough, although. from the father of one we later learned of a past infection.

Dec. 3, 1917, the thirty-one were inoculated, each with 50 million plain pertussis vaccine (stock). All the inoculations were satisfactory, with the exception of that given to one new boy who was frightened, causing the needle to slip and the dose therefore to be doubtful. All the doses were carefully measured and were therefore practically accurate. No reactions were noted, but one child complaining of a sore arm.

Up to the present time (Jan. 24, 1918) not a single case has developed in the Home. The original case was given one dose of vaccine immediately after the diagnosis was made and ceased whooping at the end of one week. The vaccine was not repeated.

111 Union Street.

* Submitted for publication Feb. 12, 1918. 